\title{
Crizotinib: aseptic abscesses in multiple organs during treatment of EML4-ALK-positive NSCLC
}

\author{
Daniel Weber $^{1} \cdot$ Miriam Decker $^{1} \cdot$ Michael Schuster $^{1} \cdot$ Sara Folz $^{1} \cdot$ Carsten Johannes Stürmer $^{2} \cdot$ Manfred P. Lutz $^{1}$ (D)
}

Received: 6 January 2021 / Accepted: 12 May 2021 / Published online: 9 August 2021

(c) The Author(s) 2021

\begin{abstract}
Purpose We report a novel side effect of Crizotinib, an oral ALK inhibitor used in the treatment of non-small cell lung cancer (NSCLC) with activating rearrangement of EML4-ALK. It expands the known spectrum of complications of Crizotinib.

Methods Clinical case report.

Results Multiple aseptic and recurrent abscesses were observed in the liver, thoracic wall as well as in both kidneys in a 75-year-old female patient suffering from NSCLC who had been treated with Crizotinib for almost 2 years. After discontinuation of the treatment the abscesses dissolved spontaneously and did not reoccur.

Conclusion Aseptic abscesses under treatment with Crizotinib are not restricted to the kidneys as described before, but can also occur in other abdominal organs as the liver and even in the thoracic wall. We postulate that this finding may point to a yet unknown not tissue-dependent mechanism of action.
\end{abstract}

Keywords Crizotinib - EML4-ALK · NSCLC $\cdot$ Aseptic abscesses $\cdot$ Side effect

Crizotinib is a targeted first-generation oral inhibitor of the anaplastic lymphoma kinase (ALK). It is commonly used for the treatment of non-small cell lung cancers (NSCLC) with activating rearrangements of EML4-ALK (Kwak et al. 2010; Soda et al. 2007). Treating advanced ALK-positive NSCLC-patients with Crizotinib improves progression-free survival, reduces symptoms and improves global quality of life when compared to chemotherapy (Shaw et al. 2013).

Common adverse events under treatment with crizotinib include malaise, nausea, vomiting, visual problems, elevated transaminases, and interstitial lung disease. In addition, several studies described the occurrence of renal cysts in up to $4 \%$ of the patients, some of them even affecting neighbouring structures (Yasuma et al. 2018).

Here, we report the case of a 75-year-old non-smoking woman who developed multiple aseptic hepatic, thoracic

Manfred P. Lutz

m.lutz@caritasklinikum.de

1 Department of Internal Medicine, Caritasklinikum St. Theresia, Rheinstrasse2, 66113 Saarbrücken, Germany

2 Centre Hospitalier de Luxembourg, Luxembourg, Luxembourg and renal abscesses under treatment with crizotinib. The patient presented initially in 2016 with an advanced adenocarcinoma staged cT4 cN2 cM1a (contralateral lung segment 10), harbouring an EML4-ALK rearrangement. After two courses of chemotherapy, second line therapy with crizotinib was started leading to complete remission within 6 months. Ten months after the start of crizotinib, a tumorous formation on the right kidney was detected. Surgical resection showed an aseptic abscess. One year later, the patient presented with fatigue, inappetence, intermittent sweating and diffuse abdominal pain. Computed tomography revealed two large abscesses with typical rim enhancement in the left-sided thoracic wall (measuring $7.2 \times 3.6 \times 1.9 \mathrm{~cm})$, left liver lobe $(9.6 \times 7.7 \times 4.5 \mathrm{~cm})$ and several others in the left kidney, right liver lobe and the interenteric space (Figs. 1, 2).

Laboratory evaluation demonstrated normal WBC count, elevated CRP (140 mg/l) and slightly elevated PCT $(0.8 \mathrm{ng} / \mathrm{ml})$ as well as increased liver function tests (below twice the ULN). Repeated blood cultures were negative. Under the suspicion of an infection, percutaneous ultrasound-guided drainage of the abscesses at the left kidney 

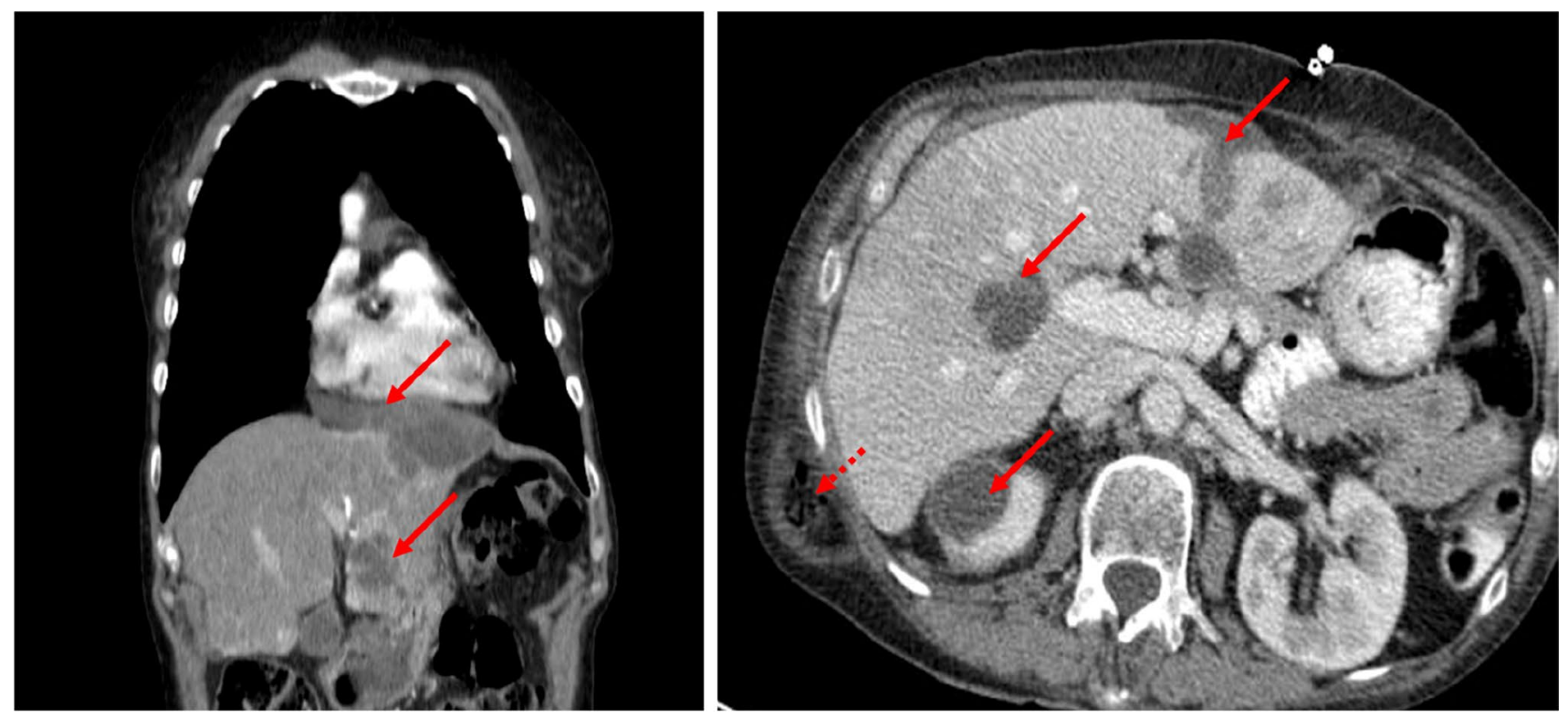

Fig. 1 Computed tomography scan after 2 years of treatment with crizotinib showing abscess formations (arrows) in the liver, the thoracic wall and kidney. The dashed arrow indicates a subcutaneous hernia

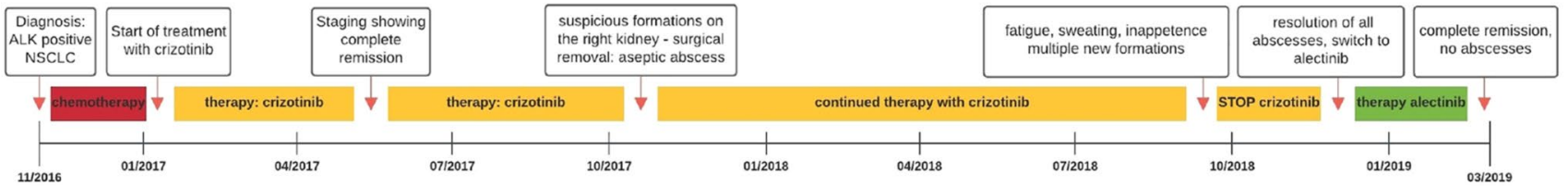

Fig. 2 Timeline of key events:

and the liver was performed. It yielded blood-stained serous fluid, cytologically described as abscess without tumour cells. Microbiological culture as well as screening for extrapulmonary tuberculosis or atypical mycobateriosis including Ziehl-Neelsen staining and PCR was negative. Endoscopic examination of the colon as well as transthoracic and transesophageal echocardiography did not find any other source of infection. Intravenous treatment with piperacillin/tazobactam was without effect. Therefore, Crizotinib was discontinued, which led to rapid improvement of the patients overall condition and symptoms. CRP and the impaired liver function tests normalised and sonographic follow-up showed ongoing global resolution of all abscesses, including those without drainage. Treatment was changed to Alectinib, with maintained complete remission without cyst formation.

In summary we describe for the first time the occurrence of multiple aseptic abscesses in various tissue types during treatment with Crizotinib. Even though renal cyst formation is a well-known complication, the postulated modulation of the c-MET and ROS1 tyrosine kinase in renal tubular epithelium does not explain our observation. We hypothesise that off-target inhibition of yet another ubiquitously expressed target may be responsible. One possible candidate could be the focal adhesion kinase, which regulates cyst formation through modulation of the focal adhesion complex and is a known target of crizotinib (Israeli et al. 2010; Troutman et al. 2016).

Author contributions The author was predominantly responsible for diagonostic interventions and treatment during hospitalisation.

Funding Open Access funding enabled and organized by Projekt DEAL. Not applicable.

Data availability Informed consent.

Code availability Not applicable. 


\section{Declarations}

Conflict of interest All authors declare no conflicts of interest.

Open Access This article is licensed under a Creative Commons Attribution 4.0 International License, which permits use, sharing, adaptation, distribution and reproduction in any medium or format, as long as you give appropriate credit to the original author(s) and the source, provide a link to the Creative Commons licence, and indicate if changes were made. The images or other third party material in this article are included in the article's Creative Commons licence, unless indicated otherwise in a credit line to the material. If material is not included in the article's Creative Commons licence and your intended use is not permitted by statutory regulation or exceeds the permitted use, you will need to obtain permission directly from the copyright holder. To view a copy of this licence, visit http://creativecommons.org/licenses/by/4.0/.

\section{References}

Israeli S, Amsler K, Zheleznova N, Wilson PD (2010) Abnormalities in focal adhesion complex formation, regulation, and function in human autosomal recessive polycystic kidney disease epithelial cells. Am J Physiol Cell Physiol 298(4):C831-C846

Kwak EL, Bang Y-J, Camidge DR, Shaw AT, Solomon B, Maki RG et al (2010) Anaplastic lymphoma kinase inhibition in nonsmall-cell lung cancer. N Engl J Med 363:1693-1703

Shaw AT, Kim D-W, Nakagawa K, Seto T, Crinó L, Ahn M-J et al (2013) Crizotinib versus chemotherapy in advanced ALK-positive lung cancer. N Engl J Med 368:2385-2394

Soda M, Choi YL, Enomoto M, Takada S, Yamashita Y, Ishikawa $S$ et al (2007) Identification of the transforming EML4-ALK fusion gene in non-small-cell lung cancer. Nature 448:561

Troutman S, Moleirinho S, Kota S, Nettles K, Fallahi M, Johnson GL, Kissil JL (2016) Crizotinib inhibits NF2-associated schwannoma through inhibition of focal adhesion kinase 1 . Oncotarget 7(34):54515-54525

Yasuma T, Kobayashi T, D’Alessandro-Gabazza CN, Fujimoto H, Ito K, Nishii Y et al (2018) Renal injury during long-term crizotinib therapy. Int J Mol Sci 19:2902

Publisher's Note Springer Nature remains neutral with regard to jurisdictional claims in published maps and institutional affiliations. 